\title{
Enhancing Mental Rotation Skills through Google SketchUp
}

\author{
Özlem Özçakır Sümen \\ Faculty of Education, Ondokuz Mayıs University, Turkey
}

Copyright $(\mathrm{C} 2018$ by authors, all rights reserved. Authors agree that this article remains permanently open access under the terms of the Creative Commons Attribution License 4.0 International License

\begin{abstract}
Spatial skills include the creation of objects in the mind and visualization them from different angles. This study examines the impact of Google SketchUp program on the development of mental rotation skills from spatial skills of eleven-year-old students. The study was conducted as a mixed method research. The quantitative research method of the study is descriptive and survey method was used. The qualitative research method used in the study is case study. In the study MGMP, MRST and interview form were used as data collection tools. A total of 170 eleven-year-old students completed MGMP test. Five students from them with low, middle and high spatial skill levels were selected for the qualitative study via purposeful sampling. Before Google SketchUp training, the mental rotation skill levels of five students were determined by applying MRST. Students were then given training on mental rotation with Google SketchUp. Then, their mental rotation levels were evaluated again. The mental rotation levels of the students were assessed according to the SOLO taxonomy. As a result of the study, it was concluded that Google SketchUp is an effective program for the development of students' mental rotation skills.
\end{abstract}

Keywords Google SketchUp, Mental Rotation Skills, SOLO Taxonomy, Spatial Skills

\section{Introduction}

Spatial thinking is about the mental processes of representing, analyzing, and drawing inferences from spatial relations [1] and it consists of the ability generate, retain, and manipulate abstract visual images [2]. Spatial ability is defined as the ability to perform tasks on the objects that require mental rotation, to understand how objects appear at different angles, and to understand how objects relate to each other in space [3]. These skills are usually mental skills related to visually understanding, manipulating, reorganizing, or interpreting relationships [4]. Although the perception of horizontality, mental rotation of objects, and location of simple figures within complex figures seem to be different from each other, these are referred to as measures of spatial ability [5]. Spatial abilities are important for higher-order thinking in science and mathematics, for the ability to generate metaphor in language and for creativity in many domains, although it was thought to be relevant with lower-order processing and concrete thought before [6]. Moreover, spatial ability and mathematics achievement are related and spatial reasoning and geometry form the foundation of much learning of mathematics and other subjects particularly for early childhood [7, 8]. In addition, mathematical ability consists of general intelligence, visual imaginary, perceptions of number and space configurations, and to retain such configurations as mental patterns [9]. For this reason, spatial skills are important in mathematics, and it is necessary to give students the opportunity to work with three-dimensional shapes, to visualize them in their minds, and to develop their spatial skills [10].

Spatial skills are important not only in the field of mathematics but also in many fields such as engineering, architecture and medicine. For success in engineering and other technological fields, the ability to visualize in three dimensions is an important cognitive skill and for engineering, the ability to mentally rotate $3-\mathrm{D}$ objects is especially important [11]. Also for success in science, technology, engineering, and mathematics (STEM) fields, spatial abilities play a critical role and high spatial ability is linked to success in STEM-related careers [1, 12]. STEM education is a popular approach around the world, with great hopes for educating students numerically. Spatial abilities are also important because they are associated with success in STEM fields. Spatial thinking is shapable and STEM education can be improved by spatial training via inexpensive spatial interventions [1].

Studies about spatial ability have identified several different factors of spatial abilities [6, 9, 13]. Two major spatial abilities are spatial orientation and spatial visualization [7, 9]. Spatial visualization involves understanding the imaginary movements of $2 \mathrm{D}$ and $3 \mathrm{D}$ objects and spatial orientation is recognizing and operating especially the relationship between different locations in space, according to your position [7]. Orientation requires 
only mental rotation of the configuration [9]. Spatial abilities consist of three types [5]: spatial perception, spatial visualization and mental rotation. It was also explained that mental rotation can be done efficiently using a Gestalt like mental rotation process analogous to physical rotation of the stimuli. Mental rotation can be defined as the ability to rotate a two or three dimensional figure rapidly and accurately [5] and it is the kind of spatial ability that a person imagines how a two- or three-dimensional object or array will appear after it has been rotated around an axis of a certain number [14].

The researches on spatial skills and mental rotation skills are quite old and have been done for different fields. For example, the dissociation between mental rotation and perspective-taking processes [15]; identifying and assessing the strategies in the spatial performance [16] and the relations between mental rotation (MR) and computer game-playing experience [14] were investigated in various studies. Moreover, the effect of dynamic geometry software Cabri 3D on the spatial abilities of mathematics teacher candidates was examined and found that Cabri 3D applications contribute to the spatial skills of teacher candidates [17]. It was found that the spatial skills of engineering students have improved via the multimedia software and the workbooks [11]. The studies about the effects of Google SketchUp from computer aided design (CAD) programs on spatial visualization and mental rotation skills are very limited. A fast remedial course based on 3D CAD modeling for improving spatial abilities of engineering students was conducted The chosen software was Google SketchUp. They found positive impact on students' spatial abilities [18]. It was aimed to determine effects of SketchUp based geometry activities and projects on spatial visualization ability of student mathematics teachers in another study. The researchers conducted an experimental research and at the end of the study there was a significant difference between two groups in favour of experimental group was seen [19]. The effectiveness of Google SketchUp on the Mental Rotation Skills of eighth grade students was also investigated [20]. In the 2011-2012 academic year, an experimental study was conducted and the results revealed that, there is no significant difference between the mean scores of the experimental and control groups' Mental Rotation Test. Because of the study's participants and method is different, it is thought that this study will contribute to the field. The problems of the research can be expressed as "What are the spatial skill levels of eleven-year-old students?" and "How does Google SketchUp training affect the mental rotation skills of eleven-year-old students?"

\section{Method}

The study was conducted as mixed method research. The quantitative research method of the study is descriptive and survey method was used to collect data. The qualitative research method used in the study is case study. "Surveys gather data at a particular time with the intention of describing the nature of existing conditions, or identifying standarts against which existing conditions can be compared, or determining the relationships that exists between events" [21]. Surveys were used to determine the spatial skill levels of eleven year old students and case study was used to determine the effect of Google SketchUp training on the development of mental rotation skills. Case study is an in-depth description and analysis of a limited system. It is concerned with the intensive study of an event, but the event to be examined is a limited case; it can be a single person, society, program, institution or policy [22, 23]. The most fundamental characteristic property of case studies is seen as the limitation of the object, that is, the case of the study [23]. In this study, the case was limited by taking the skill of "mental rotation" from the sub-dimensions of spatial skills.

\subsection{Participants}

The study was carried out at a public school. All of the students in the eleven age group training in the fifth grade (a total of 170 students) participated to the quantitative part. Then five students selected from them by maximum diversity sampling from purposeful sampling methods participated the qualitative part of the study. Five participants with the highest, middle and lowest scores were selected according to the results of MGMP test. "Although a common concern about qualitative research methods is the small sample size usually involved and the impossibility of generalizing; the purposeful sampling few but carefully selected, provides information rich cases. The sample should be large enough to be credible given the purpose of the evaluation but small enough to permit adequate depth and detail for each case in the sample" [24]. The range of min-max scores that can be taken from the MGMP test is between 0-29. The genders and MGMP test results of the five participants were given in Table 1.

Table 1. MGMP test results of the participants

\begin{tabular}{|c|c|c|c|c|c|}
\hline Student & Yusuf & Meryem & Sudenaz & Ecem & Kemal \\
\hline Gender & Male & Female & Female & Female & Male \\
\hline $\begin{array}{c}\text { MGMP } \\
\text { Score }\end{array}$ & 7points & 7 points & $\begin{array}{c}15 \\
\text { points }\end{array}$ & $\begin{array}{c}25 \\
\text { points }\end{array}$ & $\begin{array}{c}26 \\
\text { points }\end{array}$ \\
\hline
\end{tabular}

\subsection{Data Collection Tools}

The MGMP (Middle Grades Mathematics Project Spatial Visualization Test) and MRST (Mental Rotation Skill Test) were used as data collection tools in the research. MRST was developed by using the MGMP test. The MGMP Spatial Visualization Test was developed by the instructors at Michigan State University for use in the project "Middle Grades Mathematics Project" and it was translated into Turkish [25]. This test consists of 29 multiple choice questions and questions about cube 
counting, 2D to $2 \mathrm{D}$ visualization, $2 \mathrm{D}$ to $3 \mathrm{D}$ and $3 \mathrm{D}$ to $2 \mathrm{D}$ visualization, mental shape decomposing, mental completion, and mental rotation. MRST was developed by changing three of the questions about mental rotation found in the MGMP test. The questions are open-ended questions about how the given shape is viewed from different angles by being rotated. Questions were sorted so as to be from easy to hard, and isometric paper was used to make it easier for students to draw. MRST has been presented to the view of experts working in this subject and necessary corrections have been made. The mental rotation questions in MRST are given in Table 2. In addition, in order to determine the spatial skill levels of students, semi-structured interviews were conducted with students on questions. Interviews were recorded with a voice recorder and transcribed on a computer.

Table 2. Mental Rotation Skill Test (MRST)

\begin{tabular}{|l|l|}
\hline & \multicolumn{1}{|c|}{ Question } \\
\hline Besides, the front right side view of a shape was given. How is the left rear \\
side view of this shape?
\end{tabular}

\subsection{Applications}

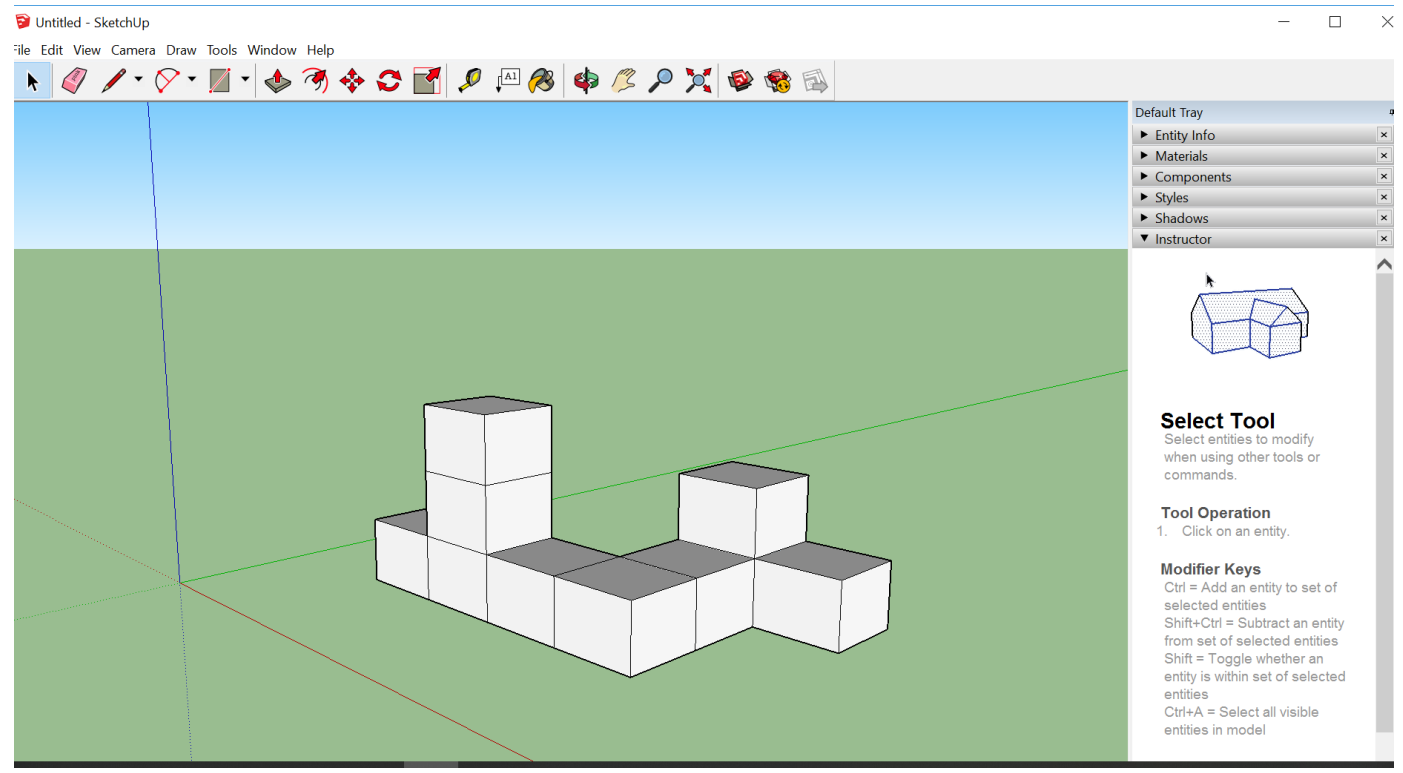

Figure 1. A sample shape made in application 


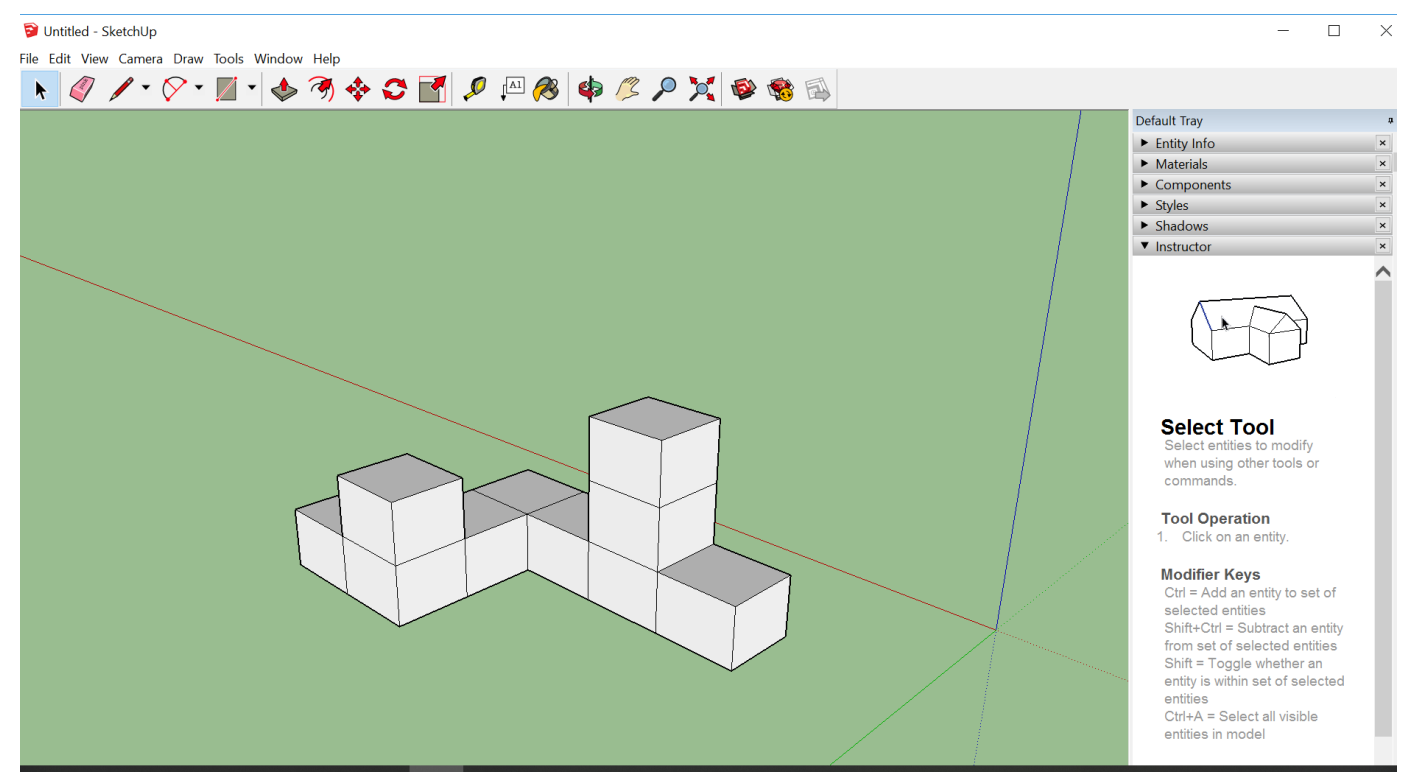

Figure 2. Another view of the sample shape

The research was carried out in three stages. In the first stage, the students in all eleven age group were applied the MGMP test to measure their spatial skill levels and according to the results of the test, five of them were selected as the participants of qualitative part. In the second stage, MRST is primarily applied to participants as a pretest and interviews were performed on questions. Then participants were trained on mental rotation with Google SketchUp, a three-dimensional design (Computer-aided design, CAD) program. Google SketchUp is a program that allows students to create three-dimensional structures with unit cubes and also allows the shape formed to be viewed from each direction $360^{\circ}$. At this stage, the program was introduced to the students, the menu, shortcut keys and how to draw were shown, and sample applications were made. The questions on mental rotation were then made by the students. A content including examples and questions about mental rotation subject was prepared to work with students before the applications. The students worked individually on the computer and they constituted all the questions themselves with the unit cubes. Later on, views of each figure from different sides were worked on, and it is provided that they comprehended views of the same shape from different angles and created them in their minds. In Figure 1 and Figure 2, examples from the study made with the Google SketchUp program were presented. As a third step in the study after the applications, MRST was again applied to the students as posttest and interviews were conducted on questions.

\subsection{Data Analysis}

The responses of the participants to the MRST were evaluated according to SOLO taxonomy (Structure of the Observed Learning Outcome-SOLO). SOLO taxonomy can be used to define intended learning outcomes, instructional ways that support them, and forms of assessment that evaluate to what extent the outcomes were achieved [26]. SOLO is applicable to a fairly wide range of items or situations requiring many different kinds of skills for different levels of students [27]. Therefore, SOLO taxonomy provides a qualitative way to classify cognitive processes [26]. SOLO is based on Piagetian descriptions of cognitive development and the levels were discernible in the Piagetian modes (sensory-motor, intuitive, concrete symbolic and formal); they almost correspond to Piaget's cognitive developmental stages [28, 29]. With this taxonomy it is possible to describe the level of thinking about the knowledge and skills that individuals require from a written or verbal answer about a particular task. Therefore, this taxonomy provides a powerful tool for assessing students' understandings and problem solving in relation to concepts [30]. SOLO taxonomy describes a hierarchy where each partial construction becomes the foundation on which learning is built [31]. It reveals the structural complexity of students' knowledge [26]. Every next level which learning is further enhanced and extended and it was discovered by observing the developmental pattern of student responses in relation to a wide variety of school subjects [29]. It is particularly applicable to the measurement and categorisation of different levels of conceptual understanding and open-ended tasks [32-34]. SOLO taxonomy has been used to classify students' responses to computer programming problems [35-38]. SOLO was also been applied to many different subjects like mathematics [39], language studies [40], biology [41].

SOLO includes five levels: prestructural (no understanding), unistructural (understanding of one element), multistructural (understanding of a number of elements but not the pattern of relationships between them), relational (understanding of the links between the elements), extended abstract (the ability to relate the 
concept to contexts and other concepts) [27]. These levels represent students' movement from the concrete to the abstract and from surface to conceptual understanding [26].
Consistency, associations, and multidimensional thinking increase as they move towards higher levels [42]. The characteristics of the levels as in the Table $3[27,28,43]$.

Table 3. The descriptions of the SOLO taxonomy levels

\begin{tabular}{|l|l|l|}
\hline SOLO description & $\begin{array}{l}\text { Some typical verbs for } \\
\text { each level }\end{array}$ & Consistency and closure \\
\hline Prestructural & Misses point & $\begin{array}{l}\text { No felt need for consistency. At this level, the answer of the students is insufficient / } \\
\text { can be denial, tautology, transduction, bound to species. The unrelated aspects of the } \\
\text { situation on which the student is working often distract the student and mislead him. } \\
\text { What they do belongs to a lower rank. }\end{array}$ \\
\hline Unistructural & $\begin{array}{l}\text { Identify, do simple } \\
\text { procedure }\end{array}$ & $\begin{array}{l}\text { No felt need for consistency. At this level the student focuses on the probing / } \\
\text { concept and can "generalize" in terms of one aspect / jumps to conclusions on one } \\
\text { aspect. However, it only uses a single direction / data associated with it. There is no } \\
\text { question of understanding the relationship of this part to its location and other } \\
\text { aspects within it. So the answer can be very inconsistent. }\end{array}$ \\
\hline Multistructural & $\begin{array}{l}\text { Enumerate describe } \\
\text { list combine do } \\
\text { algorithms }\end{array}$ & $\begin{array}{l}\text { At this level, the student uses multiple directions / verbs related to the relationship } \\
\text { without knowing the relationship between them and can "generalize" only in terms } \\
\text { of a few limited and independent aspects / come to different conclusions with same } \\
\text { data. So some inconsistencies can be seen. }\end{array}$ \\
\hline Relational & $\begin{array}{l}\text { Compare/contrast, } \\
\text { explain } \\
\text { analyse, relate, apply } \\
\text { No inconsistency within the given system. At this level, the student understands all } \\
\text { aspects related to the envelope, their place in the whole, and their relationship to each } \\
\text { other. It shows a consistent structure as a whole. The student can generalize within } \\
\text { given or experienced context using related aspects/ use induction. }\end{array}$ \\
\hline Extended abstract & $\begin{array}{l}\text { Theorize, generalize, } \\
\text { hypothesize, reflect. }\end{array}$ & $\begin{array}{l}\text { Inconsistencies resolved. At this level, the student can use deduction and induction / } \\
\text { generalize to situations not experienced /walk beyond reasoning or reach } \\
\text { generalizations. This level can represent a new way of thinking. He/she is qualified } \\
\text { to allow logically possible alternatives. }\end{array}$ \\
\hline
\end{tabular}

The most obvious difference between unistructural and multistructural is that the student responses contain more than one related data. In multistructural level, students can follow step-by-step algorithms and follow routine procedures. The ability of the learner to respond in the multistructural also requires some organizational skills that require the identification and ranking of relevant data. The transition from unistructural to multistructural requires not only the definition of information but also the development of the ability to look at this information from a broader perspective. In relational, the student should be able to integrate the elements he defines in the multistructural into a coherent system [28]. Evaluation criteria based on the SOLO taxonomy have been developed to evaluate the answers of students for MRST in order to determine their mental rotation levels in the study and were presented in Table 4.

Table 4. The evaluation criteria for MRST

\begin{tabular}{|c|c|}
\hline Prestructural (P) & $\begin{array}{c}\text { Inability to rotate the given three-dimensional structure mentally / insufficient drawing / inability to engage in the task } \\
\text { required by the current universe }\end{array}$ \\
\hline Unistructural (U) & $\begin{array}{c}\text { Focusing on the problem, but using only a single direction/inability to create a relationship among the directions that } \\
\text { belong to the same structure / inability to understand the relationship of a piece with its place within the whole and its } \\
\text { other directions /inconsistent answer /the visualized structure cannot be drawn on paper }\end{array}$ \\
\hline $\begin{array}{c}\text { Multistructural } \\
\text { (M) }\end{array}$ & $\begin{array}{c}\text { Using more than one direction related to the answer without comprehending relationships among them / ability to } \\
\text { visualize multiple rotated states of 2D and 3D structures /ability to form the structure in the given directions }\end{array}$ \\
\hline Relational (R) & $\begin{array}{c}\text { Understanding all directions related to the answer, their place in the whole, and their interrelationships /exhibiting a } \\
\text { consistent structure as a whole/ability to make a completely correct drawing }\end{array}$ \\
\hline $\begin{array}{c}\text { Extended abstract } \\
\text { (E) }\end{array}$ & deduction and induction, generalizing the ideas, representing a new way of thinking about the drawings \\
\hline
\end{tabular}

In the study, the mental rotation levels of the students before and after the training with Google SketchUp were evaluated according to the evaluation criteria in Table 4 and then the two cases were compared.

Table 5. MGMP test results of the participants

\begin{tabular}{|c|c|c|c|c|c|c|c|}
\hline \multicolumn{2}{|c|}{} & N & Mean & SD & Median & Skewness & Kurtosis \\
\hline \multirow{4}{*}{ Spatial skill points } & Female & 85 & 13,96 & 4,60 & 13,00 &, 095 &,- 919 \\
\cline { 2 - 8 } & Male & 85 & 15,98 & 5,05 & 16,00 &, 073 &,- 596 \\
\cline { 2 - 8 } & Total & 170 & 14,97 & 4,92 & 15,00 &, 132 &,- 663 \\
\hline
\end{tabular}




\section{Results}

\subsection{The Spatial Skill Levels of Eleven Year Old Students}

As seen in the Table 5, the mean of female students is 13,96 and standart deviation is 4,92 . The mean of male students 15,98 and standart deviation is 5,05 . It is seen that the mean score of male students is higher than girls. Another result is that the mean of students' spatial skills is 14,97 and standart deviation is 4,92 . The max. - min. point interval of the MGMP test is $0-29$ point. It is seen that the score of 14,97 is at middle level. Therefore, it can be said that eleven-year-old students have middle levels of spatial skills.

\subsection{Mental Rotation Levels of Students Prior to the Training with Google SketchUp}

From the students with low MGMP scores, Meryem could not answer any question in the pretest MRST application. She tried to make a three-dimensional drawing on her paper to answer the first question, but she could not draw it. Meryem, who was also unable to answer other questions, explained this situation as "I cannot imagine at all, my teacher". In this case, it can be said that the answers given by Meryem to the questions one, two and three before training are at the level of $\mathrm{P}$.

Yusuf tried to answer the first question in the pretest, but he could not rotate it mentally or transfer it as three-dimensional on paper. He could not also answer the other questions at all and stated that he could not visualize in his mind. In this case, it can be said that Yusuf is at the $\mathrm{P}$ level for all questions.

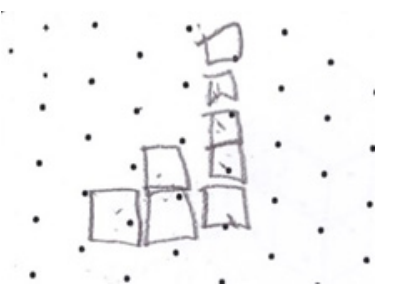

Figure 3. Sudenaz's answer to the third question in the pretest

Sudenaz answered the three questions in the pretest by drawing as two-dimensional, and it was seen that she could correctly rotate only the first question mentally, but could not draw correctly. In this case, it can be said that Sudenaz is at the level of $U$ because she can correctly rotate mentally for the first question but cannot correctly draw it on the paper. Sudenaz could not rotate and draw the other questions correctly either. "How can I draw from there to here as such? Looking from here, when I hold it like that, how does it look? When I look in between, I cannot do. I could do it if it is said from one side, that is, either from the left or from the right, but I cannot do it when it is said such as rear left, front right. That makes it difficult for me to draw," she said. In this case, Sudenaz's answers to the second and third questions appear to be in the P level. Figure 3 shows the answer of Sudenaz to the third question in the pretest.

When Ecem's answers to the pretest were examined, it was seen that she made wrong drawings in all three questions. She has correctly rotated the shapes mentally, but she made mistakes in her drawings. Figure 4 shows an answer given by Ecem in the pretest.

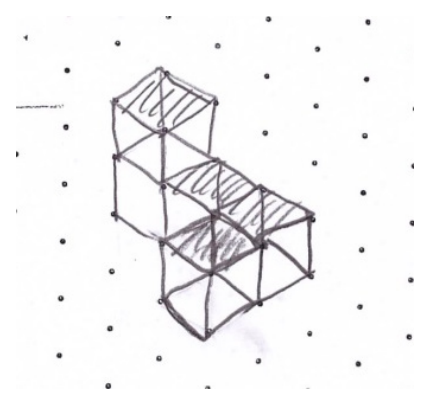

Figure 4. The answer given by Ecem to the second question in the pretest

As seen in Figure 4, Ecem missed a cube behind in her drawing and also showed the edges of the cubes that should not be visible in her drawing. Making similar mistakes in all three questions showed that Ecem was able to mentally rotate shapes correctly, but could not draw correctly. She also explained this in the interviews. In this case, it is possible to say that all answers of Ecem are at the level of U.

Kemal mentally rotated the first and second questions given in the pretest correctly and drew as three-dimensional on paper. For this reason, Kemal's answers to the questions are at the level of M. However, Kemal could not answer the third question completely. Figure 5 shows Kemal's answer to the third question in the pretest.

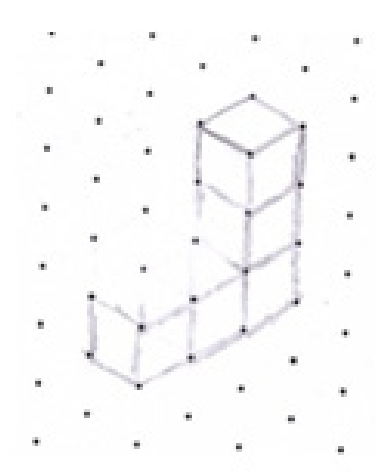

Figure 5. Kemal's answer to the third question in the pretest

As seen in Figure 5, Kemal could not complete the shape. It is seen that he cannot fully imagine and draw in his mind the rotation of the third shape which is a little more difficult than the others. In this case, Kemal's answer to the third question is at the $\mathrm{U}$ level. 


\subsection{Mental Rotation Levels of Students after Training with Google SketchUp}

After the training with Google SketchUp, it was seen that Meryem tried to draw three-dimensional drawings, but she could not correctly draw cubes on isometric paper. When asked why she could not draw, she said, "We have never used it before". Interviews and her drawings showed that she could mentally rotate shapes given in the first and second questions and look from any angle desired. Along with the shortcomings in her drawings, it was seen that she could correctly rotate objects in her mind. Meryem's answer to the first question is in Figure 6.

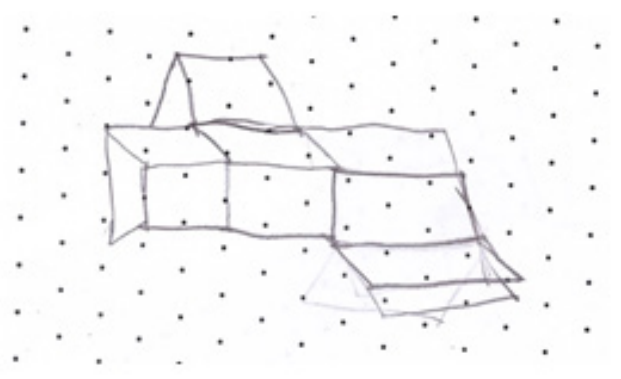

Figure 6. The Meryem's answer to the first question in the posttest

As seen in Figure 6, it is understood that Meryem rotates the shapes in her mind, but has a difficulty in drawing in three dimensions. It is seen that, when she could not draw the cube in front, she has transferred it to the paper in two dimensions. Meryem also answered the second question correctly with shortcomings. But she could draw the third question, which is more difficult, up to the half. In the third question, she could draw the single and two cubes in order, but could not draw the cube that did not appear in the back corner, and then she could not continue, leaving the drawing here. When asked why she did not continue, she said, "I cannot figure out exactly how the cube in that corner will look like, I cannot continue as I cannot draw it, the shape at that corner is very difficult." In this case, it is possible to characterize the answers Meryem gave to all three questions after the training are at the U level. Because the student said that she was able to visualize the rotated states of the three-dimensional structures given in questions in her mind, but she had trouble while transferring on paper. And she expressed this by saying "It made it easier for me to understand, but it's hard for me to draw. I forget it again while drawing. Maybe I could draw on plain paper more easily." However, when plain paper was given, she could not draw also on this paper.

Yusuf still could not make his drawings in three dimensions in posttest, he carried out them in two dimensions. Since he made the drawings in two dimensions, he could not also reflect view angles such as left-rear or front-left which are exactly required in the question on the paper. About the three-dimensional drawing, he replied as "My hand is not accustomed to this, I cannot do." In the Google SketchUp program, it was seen that he confused directions when he rotated objects, that he could not rotate in the desired direction, and that, turning to the first drawing every time, he repeatedly tried to rotate the shape in the desired direction and determined the right direction at the end.

Researcher: Now turn this shape to the right-front as in the question.

Yusuf: Let us turn it in that way. This is its view from right-front side.

Researcher: Is that all right?

Yusuf: It did not. Let me try again. Let us turn to the front again. I will turn to that side, I think to the left.

Researcher: What direction do you turn to? How are the directions of the shape? Would you show its front, its right?

Yusuf: I think here is the front, here is the rear, and that is the left side. And here is the right. I'm going to turn that side for the left.

In addition, Yusuf doubted about the unseen parts behind the shapes when drawing. This has shown that Yusuf could not imagine the unseen parts of the shapes in his mind. For example, in a question, the conversation between Yusuf and the researcher is as follows;

Yusuf: Let's take a cube now. Let's get the second cube. Researcher: Where will you put it?

Yusuf: To that place. Now let's put the third cube. Is there a cube on the rear at the bottom? I do not know that.

Researcher: I do not know. Is there?

Yusuf: I do not know either. There can be.

Researcher: Why?

Yusuf: It can not stand in the air. There should be a cube at the bottom to put the top cube. So I should put a cube there.

Yusuf's answer in fact showed that he could not imagine the shape's rear view, but he reached the right conclusion by using reasoning. One of Yusuf's drawings in the posttest was given in Figure 7. In this case, it can be said that all the answers of Yusuf after the training given are at the level of U.

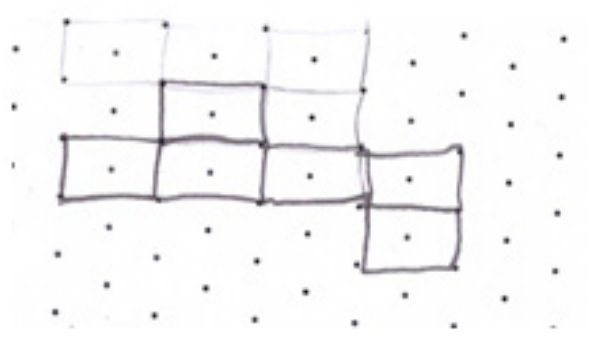

Figure 7. Yusuf's answer to the second question in the posttest

Sudenaz was able to do all drawings with the Google SketchUp program in the training, and correctly understood the rotations of shapes in all directions (front, rear, right, left). She explained her thoughts about the program as "It makes me draw very easily. [Before the program] I was trying to look from the rear. I was trying to make a plan. I do not need to make a plan on this program. 
I see directly, so I can draw. It's easier for me to imagine." In the posttest application, she was able to rotate all the questions correctly in her mind, and she correctly drew as three-dimensional on isometric paper. In this case, the level of Sudenaz 's answers to all three questions after the training can be expressed as M. Figure 8 shows an answer of Sudenaz in the posttest.

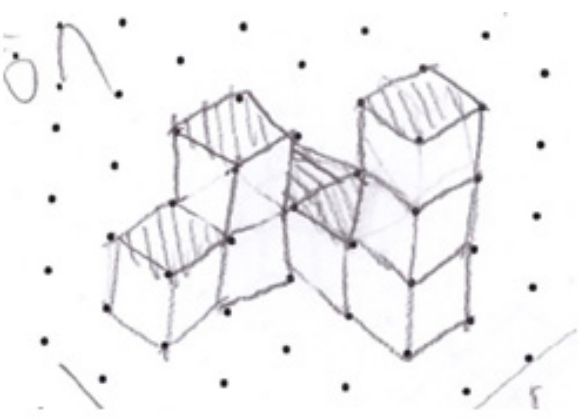

Figure 8. Sudenaz's answer to the third question in the posttest

When Ecem's answers to the posttest were examined, it was found that she did her drawings completely and accurately after Google SketchUp training. Figure 9 shows the answer of Ecem to the second question in the posttest.

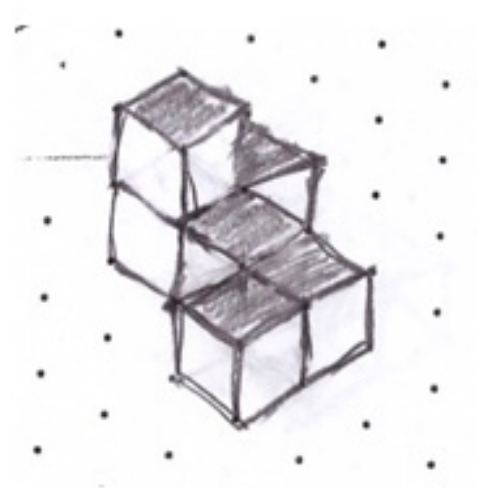

Figure 9. Ecem's answer to the second question in the posttest
As seen in Figure 9, Ecem rotated the shape, whose front left view was given in the second question, to the front left and drew on the paper. Also in other questions, she could correctly rotate the shapes in her mind in the desired directions and transferred them on paper in three dimensions. It can be said that all of Ecem's answers in the posttest are at the level of $\mathrm{M}$.

Kemal was very quick to conceive the Google SketchUp program, and he was able to do all the examples correctly. Kemal drew the first and second answers completely; having shown that he was at the level of M. After the training, the fact that he could draw the view of the third question from two different perspectives, which is the only question that he could not do at the pretest, and his answers to the questions showed that his mental rotation level was M. Figure 10 shows one of the drawings Kemal did in the third question.

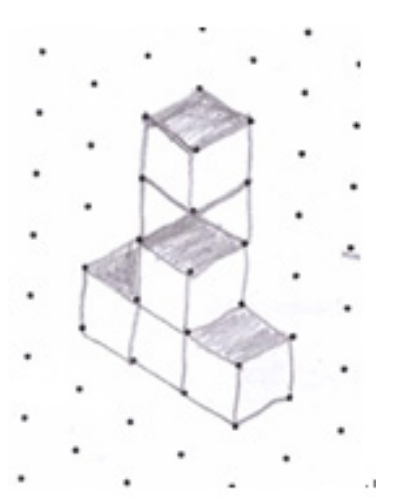

Figure 10. Kemal's answer to the third question in the posttest

\subsection{The Comparison of Students' Spatial Skill Levels before and After Training with Google SketchUp}

The levels of students' responses to the questions in the MRST test before and after the training with Google SketchUp are shown in Table 6.

Table 6. The levels of students' responses before and after the training with Google SketchUp

\begin{tabular}{|c|c|c|c|c|c|c|c|c|c|c|c|c|c|c|c|}
\hline \multirow[b]{2}{*}{$\begin{array}{c}\text { From Google } \\
\text { SketchUp } \\
\text { training }\end{array}$} & \multicolumn{3}{|c|}{ Meryem } & \multicolumn{3}{|c|}{ Yusuf } & \multicolumn{3}{|c|}{ Sudenaz } & \multicolumn{3}{|c|}{ Ecem } & \multicolumn{3}{|c|}{ Kemal } \\
\hline & 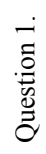 & 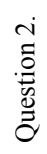 & 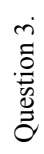 & 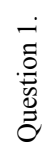 & 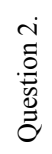 & 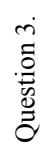 & 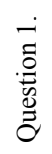 & 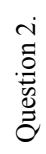 & 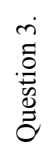 & 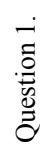 & 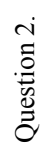 & 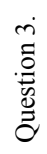 & 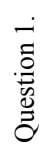 & 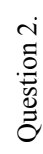 & 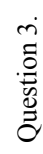 \\
\hline Before & $\mathrm{P}$ & $\mathrm{P}$ & $\mathrm{P}$ & $\mathrm{P}$ & $\mathrm{P}$ & $\mathrm{P}$ & $\mathrm{U}$ & $\mathrm{P}$ & $\mathrm{P}$ & $\mathrm{U}$ & $\mathrm{U}$ & $\mathrm{U}$ & $\mathrm{M}$ & M & U \\
\hline After & $\mathrm{U}$ & $\mathrm{U}$ & $\mathrm{U}$ & $\mathrm{U}$ & $\mathrm{U}$ & $\mathrm{U}$ & M & $\mathrm{M}$ & M & M & M & M & M & M & $\mathrm{M}$ \\
\hline
\end{tabular}

Table 6 shows that the mental rotation skills of all students have improved. It has been found that the students' abilities to imagine in three dimensions and visualize the view of an object from different directions in the mind, and accordingly to draw in three dimensions were improved thanks to Google SketchUp training. Sudenaz progressed more than the other students in this regard, and her level went up to $\mathrm{M}$ after the application, while it was $\mathrm{P}$ before the application. In addition, other students have also gone above the level they were on. 


\section{Discussion}

Spatial skills are important skills that daily life requires and also must be possessed in many professions. In particular, its interest in STEM professions has been subject to a lot of researches in recent years, and the fact that the achievement in numerical fields is proportional to the development of these skills, makes these skills particularly important. Therefore the development of spatial skills from an early age is important. In this study, the influence of mental rotation training provided by Google SketchUp on the mental rotation skills of students in the eleven age group was examined. At the end of the study, it was found that the levels of eleven year old students' spatial skills are at middle level. As a result of the pretests applied to the students in the study, it was seen that the students with low spatial skills could not perform mental rotation and could not look at shapes from different angles and could not reflect the resultant shape of the mental rotation on the paper. It was understood that even if they rotated shapes mentally, they could not make three-dimensional drawings on isometric paper. It was also seen that students with high spatial skills have also experienced some difficulties in mental rotation and drawing on paper.

After the mental rotation training performed with Google SketchUp, it was seen that the spatial skills of the students were developed. Development was achieved in the mental rotation levels of all students with low or high spatial skill scores. However, especially the mental rotation level of Sudenaz, whose spatial skill level was middle, increased to the level of $\mathrm{M}$ from $\mathrm{P}$. This result is consistent with the results of the literature. In this regard, it was investigated the relationship between mental rotation (MR) and computer game-playing experience in a study [14]. The findings imply that computer-based instructional activities can be used in schools to enhance children's spatial abilities. The fact that computer applications have developed spatial skills was also found as a result of different studies [11, 17]. There are different findings especially in the studies about the influence of Google SketchUp on spatial visualization and mental rotation skills. As a result of experimental studies on this subject, there are also studies in which Google SketchUp developed the spatial skills $[18,19]$ or did not cause any differentiation in experimental group [20]. The spatial skills levels for older ages were also investigated in other studies. For example, the spatial skill levels of prospective mathematics teachers were found to be at $\mathrm{M}$ level of SOLO taxonomy predominantly [44]. Sudenaz had a quick conception of the program, and showed that she was willing to learn by asking a lot of questions in applications. This may be particularly relevant to the motivation level of Sudenaz. It may also be due to the interest of this student has on computer applications. The other two students with high MGMP scores, Kemal and Ecem, were found to have improved their mental rotation skills after the training and reached M, a high level. Meryem and Yusuf, who had low MGMP scores, could only reach U level. This result may be due to the fact that the students need more time to understand the subject. Taking longer time and doing a study again with these students can further improve their mental rotation skills.

\section{Conclusions}

Google SketchUp is a three-dimensional design program that is easy to use and understand. Due to the positive impact of this program on the development of spatial skills, the use of it in early mathematics education will be beneficial for the development of students in mathematics and other fields.

\section{REFERENCES}

[1] Uttal, D. H., Miller, D. I., \& Newcombe, N. S. (2013). Exploring and enhancing spatial thinking: Links to achievement in science, technology, engineering, and mathematics?. Current Directions in Psychological Science, 22(5), 367-373.

[2] Lohman, D. F. (1993). Spatial ability and g. Paper presented at the first Spearman Seminar, University of Plymouth, July $21,1993$.

[3] Sutton, K. J., \& Williams, A. P. (2007). Spatial cognition and its implications for design. International Association of Societies of Design Research, (pp. 1-16), Hong Kong, China.

[4] Tartre, L. A. (1990). Spatial orientation skill and mathematical problem solving. Journal for Research in Mathematics Education, 21(3), 216-229.

[5] Linn, M.C., \& Petersen, A. C. (1985). Emergence and characterization of gender differences in spatial abilities: A meta-analysis. Child Development, 55, 1479-1498.

[6] Lohman, D. F. (1979). Spatial ability: review and re-analysis of the correlational literature. Stanford University Technical Report No. 8.

[7] Clements, D. H. (2004). Geometric and spatial thinking in early childhood education. In D. H. Clements \& J. Sarama (Eds.), Engaging young children in mathematics: Standards for early childhood mathematics education, (p. 267-297). Reston, VA: National Council of Teachers of Mathematics.

[8] Lean, G., \& Clements, M. K. (1981). Spatial ability, visual imagery, and mathematical performance. Educational Studies in Mathematics, 12(3), 267-299.

[9] McGee, M. G. (1979). Human spatial abilities: Psychometric studies and environmental, genetic, hormonal, and neurological influences. Psychological bulletin, 86(5), 889.

[10] NCTM, (National Council of Teachers of Mathematics). 
(2000). Principles and Standards For School Mathematics. Reston, Va: Author. https://www.nctm.org/uploadedFiles/S tandards_and_Positions/PSSM_ExecutiveSummary.pdf

[11] Sorby, S.A. (2009). Educational research in developing 3-D spatial skills for engineering students. International Journal of Science Education, 31(3), 459-480.

[12] Webb, R.M., Lubinski, D., \& Benbow, C.P. (2007). Spatial ability: A neglected dimension in talent searches for intellectually precocious youth. Journal of Educational Psychology, 99(2), 397-420, http://dx.doi.org/10.1037/0022-0663.99.2.397.

[13] Carroll, J. B. (1993). Human cognitive abilities: A survey of factor-analytic studies. Cambridge University Press.

[14] Lisi, R., D., \& Wolford, J. L. (2002). Improving children's mental rotation accuracy with computer game playing. The Journal of genetic psychology, 163(3), 272-282.

[15] Hegarty, M., \& Waller, D. (2004). A dissociation between mental rotation and perspective-taking spatial abilities. Intelligence, 32(2), 175-191.

[16] Schultz, K. (1991). The contribution of solution strategy to spatial performance. Canadian Journal of Psychology/ Revue canadienne de psychologie, 45(4), 474.

[17] Güven, B. \& Kosa, T. (2008). The effect of dynamic geometry software on student mathematics teachers' spatial visualization sills. The Turkish Online Journal of Educational Technology-TOJET, 7, 100 -107.

[18] Martín - Dorta, N., Saorín, J. L., \& Contero, M. (2008). Development of a fast remedial course to improve the spatial abilities of engineering students. Journal of Engineering Education, 97(4), 505-513.

[19] Kurtulus, A., \& Uygan, C. (2010). The effects of Google SketchUp based geometry activities and projects on spatial visualization ability of student mathematics teachers. Procedia-Social and Behavioral Sciences, 9, 384-389.

[20] Erkoç, M. F., Gecü, Z., \& Erkoç, Ç. (2013). The effects of using Google SketchUp on the mental rotation skills of eighth grade students. Educational Sciences: Theory \& Practice, 13(2), 1285-1294.

[21] Cohen, L., Manion, L., Morrison, K. (2002). Research methods in education (8th edition). Routledge.

[22] Glesne, C. (2012). Nitel Araştırmaya Giriş [Becoming Qualitative Researchers, Fourth Edition], A. Ersoy, P. Yalçınoğlu (Eds.). Ankara: Anı Yayıncılık.

[23] Merriam, S. B. (2013). Nitel araştırma desen ve uygulama için bir rehber [Qualitative Research A guide to design and implementation], S. Turan (Ed.). Ankara: Nobel Yayın.

[24] Patton, M. Q. (1987). How to use qualitative methods in evaluation. Sage Publications.

[25] Turgut, M. (2007). Illkögrretim II. kademede ögrencilerin uzamsal yeteneklerinin incelenmesi [Investigation of 6, 7 and 8 grade students' spatial ability]. (Doctoral dissertation) İzmir: Dokuz Eylül University.

[26] Vrachnos, E. \& Jimoyiannis, A. (2017). Secondary education students' difficulties in algorithmic problems with arrays: An analysis using the SOLO taxonomy.
Themes in Science \& Technology Education, 10(1), 31-52.

[27] Biggs, J. \& Collis, K. F. (1982). Evaluating the quality of learning: The SOLO taxonomy. New York: Academic Press.

[28] Çelik, D. (2007). Öğretmen adaylarının cebirsel düşünme becerilerinin analitik incelenmesi [Analytical Examination of the Preservice Teachers' Algebraic Thinking Skills]. (Doctoral dissertation) Trabzon: Karadeniz Technical University.

[29] Dudley, D., \& Baxter, D. (2009). Assessing levels of student understanding in pre-service teachers using a two-cycle SOLO model. Asia-Pacific Journal of Teacher Education, 37(3), 283-293.

[30] Lian, L.H., \& Idris, N. (2006). Assessing algebraic solving ability of form four students. International Electronic Journal of Mathematics Education, 1(1), 55-76.

[31] Biggs, J. \& Tang, C. (2011). Teaching for quality learning at university, what the student does? (4th edt.). McGrawHill: Society For Research İnto Higher Education \&Open University Press.

[32] Chan, C. C., Tsui, M. S., Chan, M. Y., \& Hong, J. H. (2002). Applying the structure of the observed learning outcomes (SOLO) taxonomy on student's learning outcomes: An empirical study. Assessment \& Evaluation in Higher Education, 27(6), 511-527.

[33] Hattie, J.A.C., \& Brown, G.T.L. (2004). Cognitive processes in asTTle: The SOLO taxonomy. Assessment Tools for Teaching and Learning Technical Report \#43. Auckland: University of Auckland \& Ministry of Education, New Zealand. https://auckland.rl.talis.com/items/FCAC960F-E73F-55580946-73168F2E0E1B.html

[34] Smith, T. W. \& Colby, S. A. (2007). Teaching for deep learning. The Clearing House: A Journal of Educational Strategies, Issues and Ideas, 80(5), 205-210. DOI: 10.3200/TCHS.80.5.205-210

[35] Clear, T., Whalley, J., Lister, R., Carbone, A., Hu, M., Sheard, J., Simon, B., \& Thomson, E. (2008). Reliably classifying novice programmer exam responses using the SOLO taxonomy. In S. Mann \& M. Lopez (Eds.), 21st Annual Conference of the National Advisory Committee on Computing Qualifications (pp. 23-30). Auckland: NACCQ.

[36] Sheard, J., Carbone, A., Lister, R., Simon, B., Thomson, E., \& Whalley, J. L. (2008). Going SOLO to assess novice programmers. Proceedings of the 13th annual conference on Innovation and technology in computer science education, (pp. 209-213).

[37] Corney, M., Fitzgerald, S., Hanks, B., Lister, R., McCauley, R., \& Murphy, L. (2014). 'Explain in plain english' questions revisited: data structures problems. Proceedings of the 45th ACM Technical Symposium on Computer Science Education (pp. 591-596). New York: ACM Press.

[38] Seiter, L. (2015). Using SOLO to classify the programming responses of primary grade students. Proceedings of the 46th ACM Technical Symposium on Computer Science Education (SIGCSE '15) (pp. 540-545). New York: ACM.

[39] Chick, H. (1998). Cognition in the formal modes: research 
mathematics and the SOLO taxonomy. Mathematics Education Research Journal, 10(2), 4-26.

[40] Campbell, J., Smith, D., \& Brooker, R. (1998). From conception to performance: How undergraduate students conceptualise and construct essays. Higher Education, $36(4), 449-469$.

[41] Lake, D. (1999). Helping students to go SOLO: Teaching critical numeracy in the biological sciences. Journal of Biological Education, 33(4), 191-198.

[42] Biggs, J. \& Collis, K. (1991). Multimodal learning and the quality of intelligent behaviour. In $\mathrm{H}$. Rowe (Ed.), Intelligence, reconceptualization and measurement.
Laurence Erlbaum Assoc: New Jersey.

[43] Biggs, J. (2003). Aligning teaching and assessing to course objectives. Teaching and learning in higher education: New trends and innovations, University of Aveiro (Portugal), (pp. $1-9)$.

https://www.dkit.ie/ga/system/files/Aligning Reaching an d_Assessing_to_Course_Objectives_John_Biggs.pdf

[44] Göktepe, S., \& Özdemir, A. Ş. (2013). İlköğretim matematik öğretmen adaylarının uzamsal görselleștirme becerilerinin SOLO modeli ile incelenmesi [Examing Elementary Mathematics Teacher Landidates' Special Visualization Skills by SOLO Model]. Kalem Eğitim ve Insan Bilimleri Dergisi, 3(2), 91-146. 